\title{
L-Lysine Decreases Nitric Oxide Production and Increases Vascular Resistance in Lungs Isolated from Lipopolysaccharide-Treated Neonatal Pigs
}

\author{
BARNEY W. CARTER, JR, LOUIS G. CHICOINE, AND LEIF D. NELIN \\ Vascular Physiology Group [B.W.C., L.G.C., L.D.N.], Department of Pediatrics, University of New \\ Mexico HSC, Albuquerque, NM 87131 U.S.A.; Center for Developmental Pharmacology and Toxicology \\ [L.D.N.], Center for Gene Therapy [L.G.C.], Columbus Children's Research Institute, Department of \\ Pediatrics, The Ohio State University, Columbus, OH 43205 U.S.A.
}

\begin{tabular}{|c|c|}
\hline \multicolumn{2}{|c|}{ ABSTRACT } \\
\hline 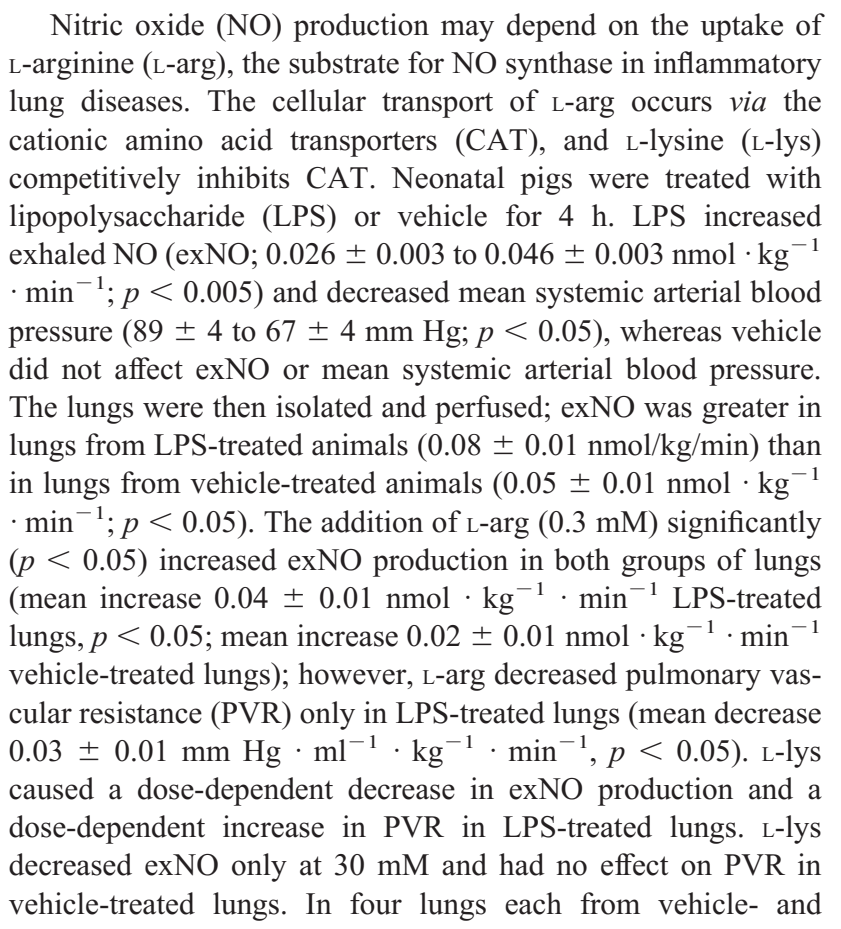 & 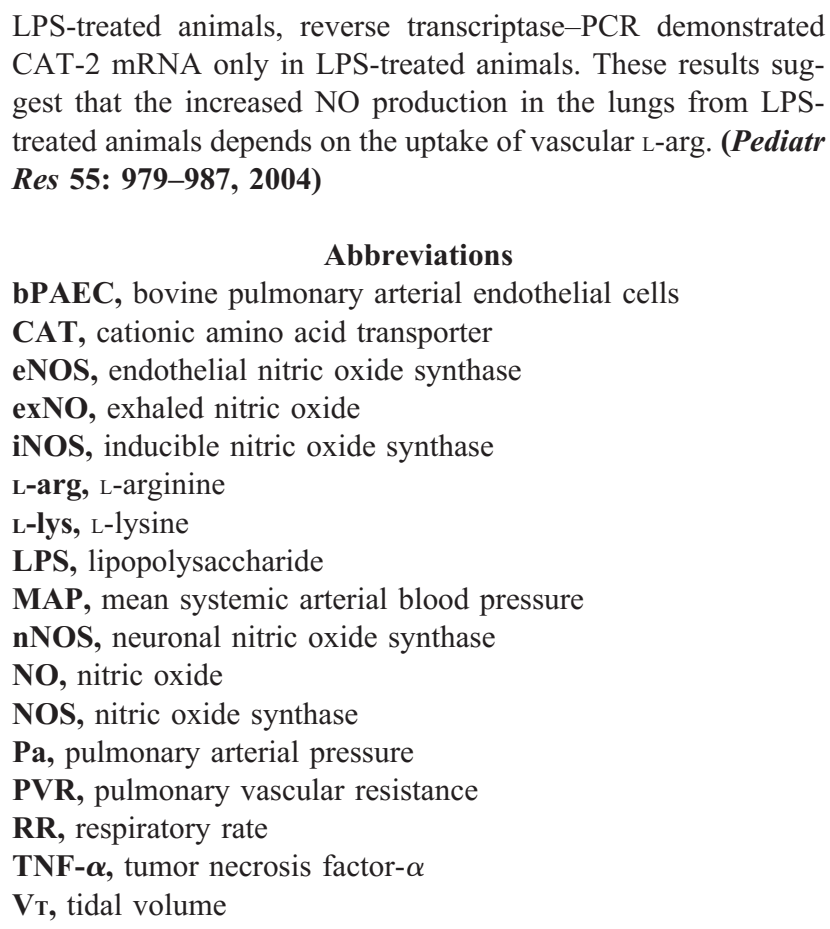 \\
\hline
\end{tabular}

Increased nitric oxide (NO) production is associated with diseases characterized by an inflammatory response, for example, acute respiratory distress syndrome and septic shock (1-4). Activation of inflammatory cells during infection causes the release of cytokines such as tumor necrosis

Received October 8, 2003; accepted February 5, 2004

Correspondence: Leif D Nelin, M.D., Section of Neonatology, Children's Hospital, 700 Children's Drive, Columbus, OH 43205 U.S.A.; e-mail: NelinL@pediatrics.ohio-state.edu This work was supported by a Grant-in-Aid from the American Heart Association, Desert Mountain Affiliate (L.D.N.) and National Heart, Lung and Blood Institute Grant HL-004050 (L.G.C.).

DOI: 10.1203/01.pdr.0000127722.55965.b3 factor- $\alpha$ (TNF- $\alpha$ ), IL- $1 \beta$, and interferon- $\gamma$, and these cytokines have been found to increase NO synthase (NOS) expression, resulting in increased NO production (5-7). The inflammation-induced increase in NO production potentiates vascular complications and participates in the pathogenesis of lung injury $(1,2,4)$.

$\mathrm{NO}$ is produced by the oxidation of L-arginine (L-arg) to L-citrulline and NO, which is catalyzed by NOS. There are three well-characterized isoforms of NOS: endothelial NOS (eNOS), neuronal NOS (nNOS), and inducible NOS (iNOS). eNOS and nNOS are for the most part constitutively expressed, and iNOS expression is largely induced by various stimuli, 
including inflammatory stimuli $(1-4,7-10)$. L-Arg is transported into cells by a family of cationic amino acid transporters (CAT), which were first described and characterized by Wang et al. (11) in 1991. Four members of the CAT family have been cloned and identified (12), of which CAT-1 and CAT-2 are found in the lung $(8,12)$. CAT-2 expression in some cell types and tissues can be regulated by various stimuli $(7-9,13,14)$. For example, we have found that iNOS and CAT-2 mRNA expression are increased in lungs from rats exposed to intratracheal silica compared with controls (8). We have also found that iNOS protein expression and the production of NO are increased in cultured bovine pulmonary arterial endothelial cells (bPAEC) stimulated by the combination of lipopolysaccharide (LPS) and TNF- $\alpha$ (7). The uptake of L-arg in these LPS/TNF- $\alpha$-stimulated bPAEC and the expression of CAT-2 mRNA were also increased (7). This led us to hypothesize that LPS treatment increases both NO production and L-arg uptake in the lung and that the increase in L-arg uptake serves to provide sufficient substrate, L-arg, to NOS to maintain this increased NO production. We addressed this hypothesis by studying the role of L-arg uptake in NO production in a model of cytokine-induced lung injury in the neonatal pig. The model consisted of neonatal pigs treated with either LPS or vehicle. Four hours after the administration of either LPS or vehicle, the lungs were isolated and perfused. We measured exhaled NO (exNO) production and vascular pressures before and after adding L-arg to the perfusate and then during the addition of increasing doses of L-lysine (L-lys) to the perfusate. We used L-lys as a competitive antagonist of L-arg uptake, because L-lys is also transported by the CAT family of amino acid transporters (12), and L-lys has been shown to inhibit L-arg transport in previous studies $(9,10)$. Finally, we measured CAT-2 mRNA expression in lungs from vehicle- and LPS-treated animals.

\section{METHODS}

All protocols used in this study were reviewed and approved by the Institutional Animal Care and Use Committee of the University of New Mexico School of Medicine. Two-week-old neonatal piglets were placed into either LPS-treated $(n=12)$ or vehicle-treated ( $n=14$ ) groups. Group selection was randomized and comprised a total of 26 animals from 11 different litters. Animals were cared for in the University of New Mexico School of Medicine animal research facility and fed a diet of sow milk replacer and water ad libitum.

\section{Intact Animal Preparation}

On the day of study, animals were anesthetized with a mixture of xylazine (3.3 mg/kg i.m.) and telazol $\mathrm{HCl}$ (7.5 mg/kg i.m.). A midline incision was made in the neck, and a carotid artery catheter that allowed for the measurement of arterial blood pressure as well as the administration of additional anesthetic (pentobarbital $2 \mathrm{mg} / \mathrm{kg}$ i.v. every hour) was placed. A tracheotomy tube was placed and connected to a piston-type ventilator (Harvard Apparatus, Braintree, MA, U.S.A.). After catheter insertion and tracheotomy, intact neonatal pigs were ventilated with a gas mixture of $21 \% \mathrm{O}_{2}$ in $\mathrm{N}_{2}$. Adjustments were made to tidal volume
$\left(\mathrm{V}_{\mathrm{T}}\right)$ and/or respiratory rate (RR) to maintain physiologic arterial $\mathrm{pH}(7.42 \pm 0.02), \mathrm{PCO}_{2}(33 \pm 2 \mathrm{~mm} \mathrm{Hg})$, and $\mathrm{Po}_{2}(102 \pm 13 \mathrm{~mm}$ $\mathrm{Hg}$ ). Once the appropriate arterial blood gases were obtained, $\mathrm{V}_{\mathrm{T}}$ and RR were held constant throughout the remainder of the 4-h experimental protocol. A portion of the exhaled gas was continuously passed through a chemiluminescence NO analyzer (270B NOA; Sievers, Boulder, CO, U.S.A.) for measurement of exNO. After stabilization, anesthetized neonatal pigs were given LPS (Sigma Chemical Co. Chemical, St. Louis, MO, U.S.A.) $1 \mathrm{mg} / \mathrm{kg}$ in $3 \mathrm{~mL}$ of saline or $3 \mathrm{~mL}$ of saline (as a vehicle control) i.p. At the end of the 4-h experimental protocol, animals were given heparin (1000 U/kg i.v.) and were exsanguinated, and the lungs were isolated and perfused as described below.

\section{Isolated Lung Preparation}

The lungs were isolated and perfused as previously described (15-17). The lungs were isolated so that the pulmonary vascular effects of L-arg and L-lys treatment could be studied under precisely controlled hemodynamic conditions and to avoid potentially confounding CNS and/or hormonal effects. Briefly, a midline sternotomy was performed, and saline-filled cannulas were placed in the main pulmonary artery and left atrium. The cannulas were connected to a perfusion circuit that was filled with a Krebs Ringer bicarbonate solution containing 5\% dextran (MW 70,000). The Krebs Ringer bicarbonate was made fresh on the day of experimentation, and each liter contained $7.58 \mathrm{~g}$ of NaCl, $0.40 \mathrm{~g}$ of $\mathrm{KCl}, 0.06 \mathrm{~g}$ of $\mathrm{NaHPO}_{4}$, $0.205 \mathrm{~g}$ of $\mathrm{MgSO}_{4}, 1.6 \mathrm{~g}$ of $\mathrm{NaHCO}_{3}, 0.26 \mathrm{~g}$ of $\mathrm{CaCl}_{2}$, and $0.991 \mathrm{~g}$ of glucose. The perfusion circuit consisted of a rotary pump that continuously circulated perfusate from a heated reservoir to the pulmonary arterial cannula via a bubble trap; perfusate left the lungs via the left atrial cannula and drained back to the reservoir. Initial lung perfusion was nonrecirculating until the perfusate exiting the lung was nearly clear of blood, at which point recirculating perfusion was established. The resulting perfusate hematocrit concentration was $<1 \%$. The volume of the recirculating perfusate was adjusted to a total of $250 \mathrm{~mL}$. The flow rate of the perfusion circuit was increased incrementally to $50 \mathrm{~mL} \cdot \mathrm{kg}^{-1} \cdot \min ^{-1}$ and maintained constant at $50 \mathrm{~mL} \cdot \mathrm{kg}^{-1} \cdot \min ^{-1}$ throughout the experiment. Pulmonary arterial $(\mathrm{Pa})$ and left atrial $(\mathrm{Pv})$ pressures were continuously measured. Pv was set at $2 \mathrm{~mm} \mathrm{Hg}$ by adjusting the height of the reservoir and then held constant at $2 \mathrm{~mm} \mathrm{Hg}$ throughout the experimental protocol. The lungs were ventilated with a constant $\mathrm{V}_{\mathrm{T}}$ and $\mathrm{RR}$ using a gas mixture containing $21 \% \mathrm{O}_{2}, 6 \% \mathrm{CO}_{2}$, and balance $\mathrm{N}_{2}$. Perfusate $\mathrm{pH}$ was $7.35 \pm 0.02$, perfusate $\mathrm{PCO}_{2}$ was $40 \pm 2 \mathrm{~mm} \mathrm{Hg}$, and perfusate $\mathrm{PO}_{2}$ was $137 \pm 8 \mathrm{~mm} \mathrm{Hg}$. exNO, $\mathrm{Pa}$, and $\mathrm{Pv}$ were recorded throughout the experiment using data acquisition software (CODAS, Dataq Instruments, Akron, OH, U.S.A.). We chose to measure exNO as a marker of isolated lung NO production because we have previously found that changes in exNO parallel changes in perfusate nitrites/nitrates $(8,16)$, and because the volume of distribution in the airways is smaller than the volume of distribution in the vascular bed, the time course for observing changes in lung exNO production is much shorter than for perfusate nitrites/nitrates. 


\section{Reverse Transcriptase-PCR for CAT-2}

Reverse transcriptase-PCR (RT-PCR) for CAT-2 was performed as previously described $(7,8)$. Briefly, RT reactions (40 $\mu \mathrm{L}$ ) contained 20 units of avian Moloney Virus (AMV-RT; Promega, Madison, WI, U.S.A.), $2 \mu \mathrm{g}$ of total tissue RNA, 5 $\mu \mathrm{M}$ oligo $(\mathrm{dT})_{16}, 1 \mathrm{mM}$ deoxynucleotide triphosphates (dNTPs), and $3 \mathrm{mM} \mathrm{MgCl} 2$. Tissue RNA and oligo(dT) 16 were held at $65^{\circ} \mathrm{C}$ for $5 \mathrm{~min}$, then $4^{\circ} \mathrm{C}$ for $5 \mathrm{~min}$. The remainder of the RT reaction mixture was then added and incubated at $21^{\circ} \mathrm{C}$ for $10 \mathrm{~min}, 42^{\circ} \mathrm{C}$ for $1 \mathrm{~h}, 94^{\circ} \mathrm{C}$ for $5 \mathrm{~min}$, and then returned to $4^{\circ} \mathrm{C}$ and frozen at $-20^{\circ} \mathrm{C}$ until used for PCR. PCR reactions contained $1 \mu \mathrm{M}$ oligonucleotide primers for CAT-2. The CAT-2 primers used were forward 5'-AAC GTG CTT TTA TGC CTT TGT-3' and reverse 5'-GGT GAC CTG GGA CTC GCT CTT-3' $(7,8,14)$. Additional components of the PCR reaction included $5.0 \mu \mathrm{L}$ of RT product, $3 \mathrm{mM} \mathrm{MgCl} 2$, PCR buffer II (Perkin-Elmer, Downers Grove, IL, U.S.A.), $0.2 \mathrm{mM}$ dNTPs and 2.5 units of Amplitaq Polymerase (Perkin Elmer). PCR reactions were denatured at $94^{\circ} \mathrm{C}$ for $5 \mathrm{~min}$ and then cycled at $94^{\circ} \mathrm{C}$ for $45 \mathrm{~s}, 55^{\circ} \mathrm{C}$ for $45 \mathrm{~s}$, and $72^{\circ} \mathrm{C}$ for $2 \mathrm{~min}$ for a total of 35 cycles. Final extension was $5 \mathrm{~min}$ at $72^{\circ} \mathrm{C}$. PCR products were separated and sized by $1 \%$ agarose gel electrophoresis. Gels were visualized using Gel Scan software. PCR product size was the expected $613 \mathrm{bp}$ for CAT-2.

\section{Experimental Protocols}

Intact animals. To ensure that this model resulted in physiologically relevant increased NO production, we determined the effect of LPS treatment on exNO and mean systemic arterial blood pressure (MAP) in intact neonatal pigs. After an equilibration period of 30-60 min, either LPS $(n=8)$ or vehicle $(n=10)$ was administered i.p. MAP was measured from the carotid artery catheter, and expiratory gas was continuously sampled for exNO while ventilation was held constant as described above. The exNO and MAP were measured before LPS or vehicle administration and $4 \mathrm{~h}$ after LPS or vehicle administration.

Isolated lung L-arg and exNO. To determine the effects of exogenous L-arg on lung NO production and pulmonary vascular resistance (PVR), we studied the isolated perfused lungs from either LPS-treated $(n=7)$ or vehicle-treated $(n=9)$ animals (one of the LPS-treated pigs and one of the vehicletreated pigs did not have an isolated perfused lung study done). Baseline exNO and $\mathrm{Pa}$ were measured after a 20 -min equilibration period at constant ventilation, perfusate flow rate of 50 $\mathrm{mL} \cdot \mathrm{kg}^{-1} \cdot \mathrm{min}^{-1}$, and $\mathrm{Pv}$ of $2 \mathrm{~mm} \mathrm{Hg}$. L-Arg was then added to the perfusate to achieve a final concentration of $0.3 \mathrm{mM}$, and 20 min later, exNO and $\mathrm{Pa}$ were again measured as described above.

Isolated lung L-lys and exNO. To determine the effects of inhibiting L-arg uptake on exNO production and PVR, we studied the isolated perfused lungs from either LPS- or vehicletreated animals. After the exNO and $\mathrm{Pa}$ measurements were obtained in the 16 lungs described above, L-lys was added to the recirculating perfusate to achieve final concentrations of 1 , 3,10 , and $30 \mathrm{mM}$. These concentrations of L-lys were chosen, given that the perfusate contained $0.3 \mathrm{mM} \mathrm{L}$-arg and that $\mathrm{L}-\mathrm{lys}$ is a competitive inhibitor of L-arg uptake, to yield perfusate concentrations of L-lys that were $\sim 100$-fold compared with L-arg perfusate concentrations. Twenty minutes after each addition of L-lys, exNO and $\mathrm{Pa}$ were measured at constant ventilation, perfusate flow rate of $50 \mathrm{~mL} \cdot \mathrm{kg}^{-1} \cdot \mathrm{min}^{-1}$, and $\mathrm{Pv}$ of $2 \mathrm{~mm} \mathrm{Hg}$.

Lung CAT-2 mRNA expression. For determining the effect of LPS treatment on the expression of CAT-2 mRNA in neonatal pig lungs, total RNA was isolated from lungs of LPS-treated $(n=4)$ and vehicle-treated $(n=4)$ animals using Trizol (Life Technologies, Frederick, MD, U.S.A.) according to the manufacturer's protocol and analyzed using RT-PCR as described above.

\section{Statistical Analysis}

exNO concentration ( $\mathrm{ppb}$ ) was determined by calibrating the NO analyzer daily using authentic NO $\left(1 \mathrm{ppm}\right.$ in $\left.\mathrm{N}_{2}\right)$ mixed with NO-free $\mathrm{N}_{2}$ using precision flowmeters. The NO detection limit was $0.5 \mathrm{ppb}$ ( $\mathrm{vol} / \mathrm{vol})$. exNO concentration was calculated as the difference between the NO concentration in the exhaled gas and the NO concentration in the inhaled gas. Although the NO concentration in the inhaled gas rarely exceeded the detection limit, using the NO concentration of the inhaled gas corrected for potential baseline drift of the $\mathrm{NO}$ analyzer. exNO production rate in $\mathrm{nmol} \cdot \mathrm{min}^{-1} \cdot \mathrm{kg}$ body weight ${ }^{-1}$ was calculated using minute ventilation $\left(\mathrm{V}_{\mathrm{T}} \times \mathrm{RR}\right)$ and the exNO concentration (ppb) as previously described $(6,8)$. The PVR was calculated as $(\mathrm{Pa}-\mathrm{Pv}) /$ flow rate $\left(50 \mathrm{~mL} \cdot \mathrm{min}^{-1} \cdot \mathrm{kg}^{-1}\right)$. L-Lys data are expressed as the change from baseline values before the L-lys addition. All values are presented as the mean \pm SE. The LPS- and vehicle- treated groups were compared using one-way ANOVA, and significant differences were identified using a Newman-Keuls post hoc test. The effect of adding $0.3 \mathrm{mM}$ L-arg to the perfusate on exNO and PVR was compared within groups using a paired $t$ test. The effect of increasing doses of L-lys within each group were compared using repeated measures ANOVA, and significant differences were identified using a Newman-Keuls post hoc test. The correlation coefficients for exNO and MAP, as well as change in exNO and change in PVR, were calculated using Sigmaplot software (Jandel Scientific, San Rafael, CA, U.S.A.). Differences were considered significant at $p<0.05$.

\section{RESULTS}

Intact animals. Figure 1 shows a typical tracing of exNO concentration and MAP during the 4-h experimental period from an LPS-treated pig. It can be seen in this example that exNO concentration at a constant ventilation began to increase and that MAP began to decrease at $\sim 90$ min after LPS injection. At the end of the 4-h incubation period, there was an $\sim 80 \%$ increase in mean exNO in the LPS-treated animals compared with time 0 (Fig. 2), whereas there was no significant change in exNO in the vehicle-treated animals compared with baseline (Fig. 2). The LPS-treated animals had an $\sim 25 \%$ decrease in the mean MAP during the 4-h experimental period (Fig. 3). Conversely, the vehicle-treated pigs demonstrated a small $(\sim 10 \%)$ but significant increase in mean MAP after $4 \mathrm{~h}$ 


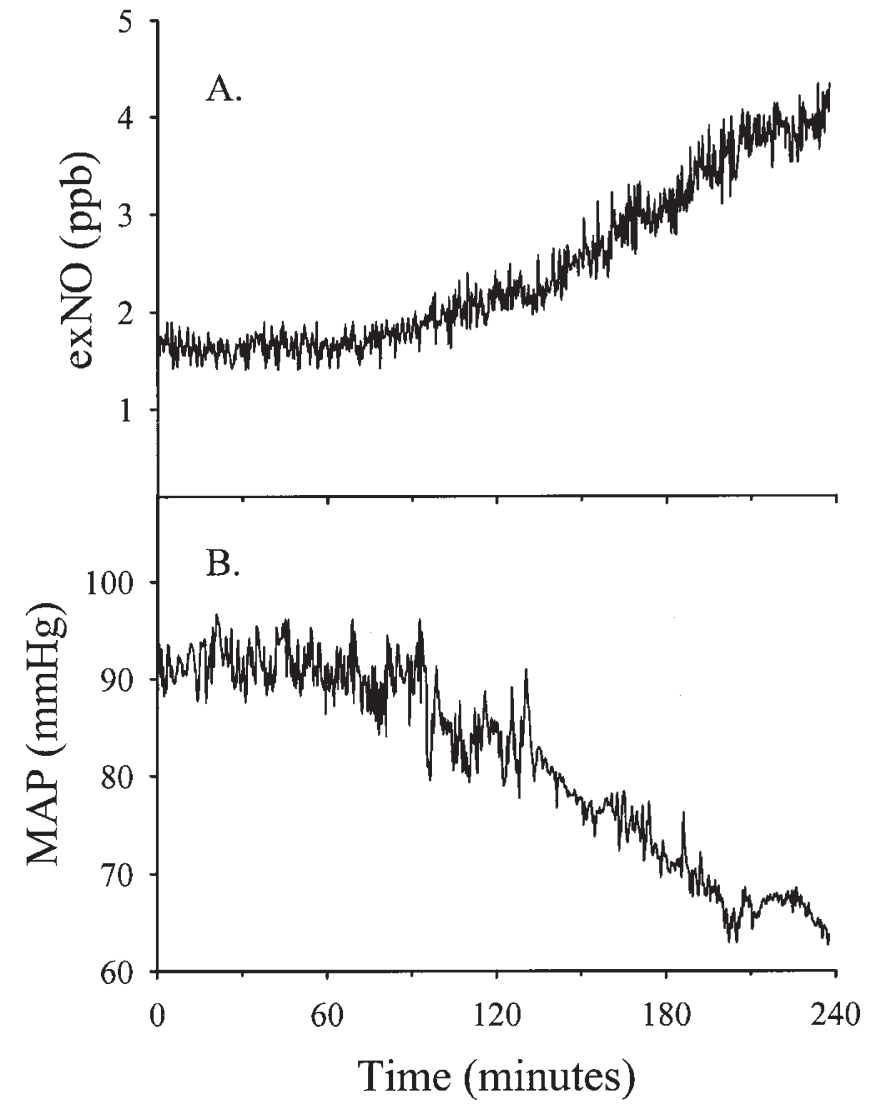

Figure 1. A typical experimental tracing in the intact animal. Typical experimental tracing of exNO concentration in ppb $(A)$, and MAP in $\mathrm{mm} \mathrm{Hg}$ $(B)$ during the 4-h incubation period after treatment with $1 \mathrm{mg} / \mathrm{kg}$ LPS i.p. in an intact neonatal pig. The exNO concentration increased and the MAP decreased starting at $\sim 90 \mathrm{~min}$, and these trends continued until the end of the 4-h experimental period.

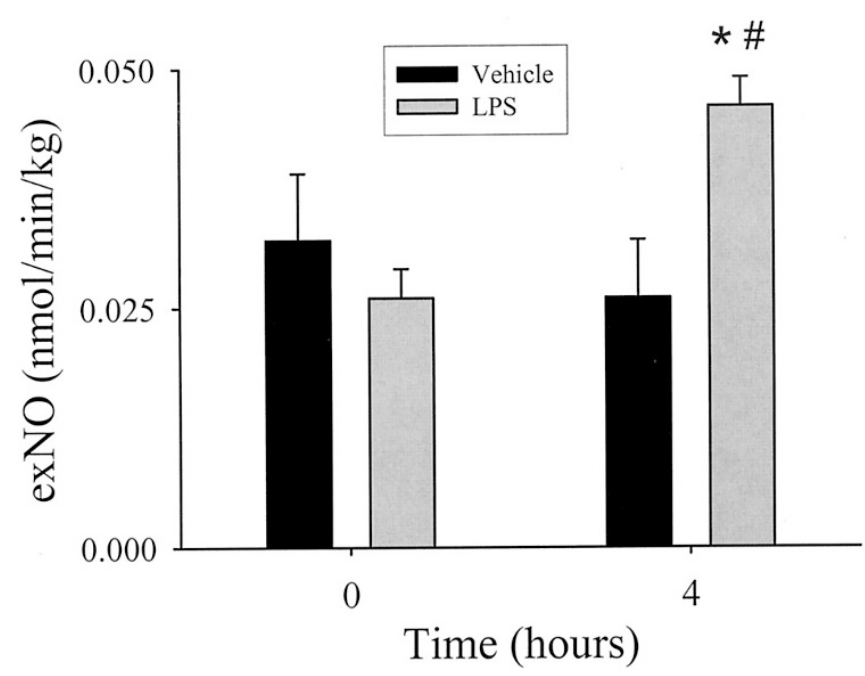

Figure 2. LPS increased exNO production in the intact animal. exNO production at 0 and $4 \mathrm{~h}$ after injection of either vehicle $(\square)$ or LPS $(\square)$ in intact neonatal pigs. Values are mean $\pm \mathrm{SE}(n=10$ vehicle and $n=8$ LPS $)$. *Different from starting value, $p<0.01$; \#LPS-treated different from vehicletreated at $4 \mathrm{~h}, p<0.05$.

compared with baseline (Fig. 3). The MAP at $4 \mathrm{~h}$ was negatively correlated $(p<0.001)$ with the exNO concentration at $4 \mathrm{~h}$ (Fig. 4), such that animals with the highest MAP had the lowest exNO concentration.

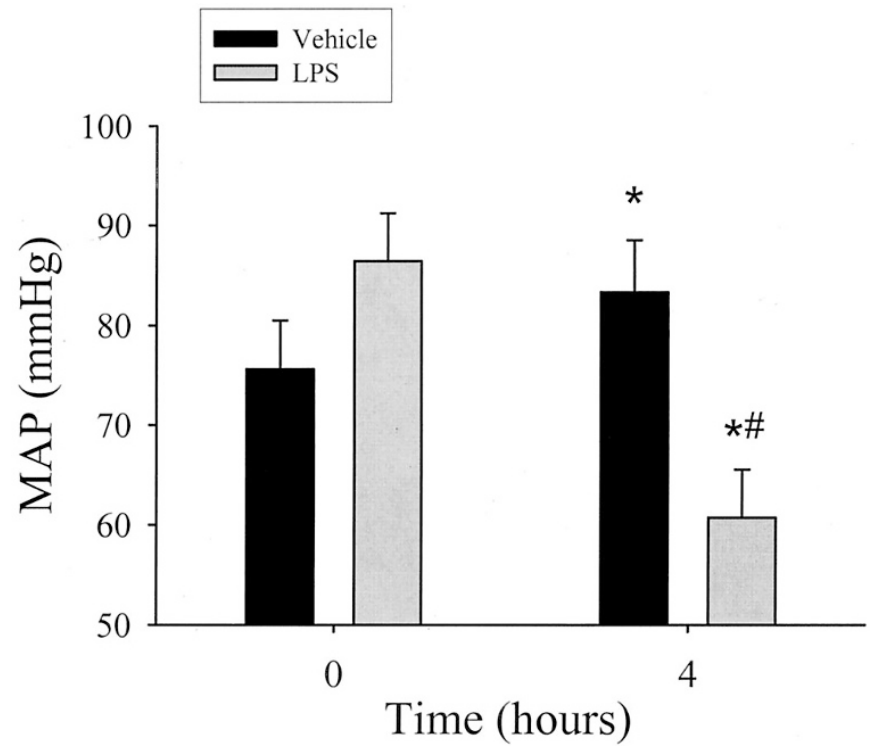

Figure 3. LPS decreased MAP in the intact animal. MAP at 0 and $4 \mathrm{~h}$ after injection of either vehicle $(\square)$ or LPS $(\square)$ in intact neonatal pigs. Values are mean $\pm \mathrm{SE}(n=10$ vehicle and $n=8 \mathrm{LPS}) . *$ Different from starting value, $p<0.05$; \#LPS-treated different from vehicle-treated at $4 \mathrm{~h}, p<0.01$.

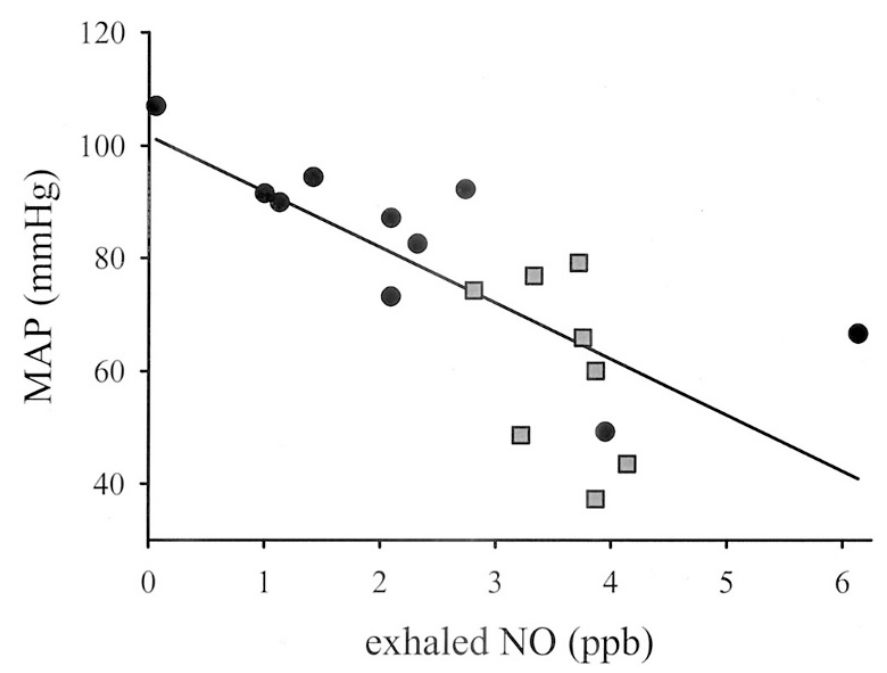

Figure 4. exNO negatively correlated with MAP. MAP at $4 \mathrm{~h}$ after either vehicle or LPS treatment plotted against the exNO concentration in ppb. $\bullet$ vehicle-treated animals; $\square$, LPS-treated animals. Note that the black circles tend to be at higher MAP and lower exNO than the gray squares. The solid line is the linear regression for all of the animals $(n=18)$; the equation for the line is $y=-9.92 x+101.7$, and the $r$ value is $-0.73(p<0.001)$. Thus, the lower the exNO, the higher the MAP in these animals, regardless of treatment.

Isolated lung L-arg and exNO. LPS treatment resulted in a greater $(p<0.05)$ exNO production $\left(0.08 \pm 0.01 \mathrm{nmol} \cdot \mathrm{kg}^{-1}\right.$ $\left.\cdot \min ^{-1}\right)$ in the isolated perfused lungs than did vehicle treatment $\left(0.05 \pm 0.01 \mathrm{nmol} \cdot \mathrm{kg}^{-1} \cdot \min ^{-1}\right)$. Adding $\mathrm{L}$-arg to the perfusate caused an $\sim 40 \%$ increase in mean exNO production rate in lungs isolated from vehicle-treated animals (Fig. 5). Adding L-arg to the perfusate caused an $\sim 50 \%$ increase in mean exNO production rate in lungs isolated from LPS-treated animals (Fig. 5). Although the Pa, at constant flow rate and $\mathrm{Pv}$, tended to be higher in lungs isolated from vehicle-treated animals compared with lungs isolated from LPS-treated ani- 


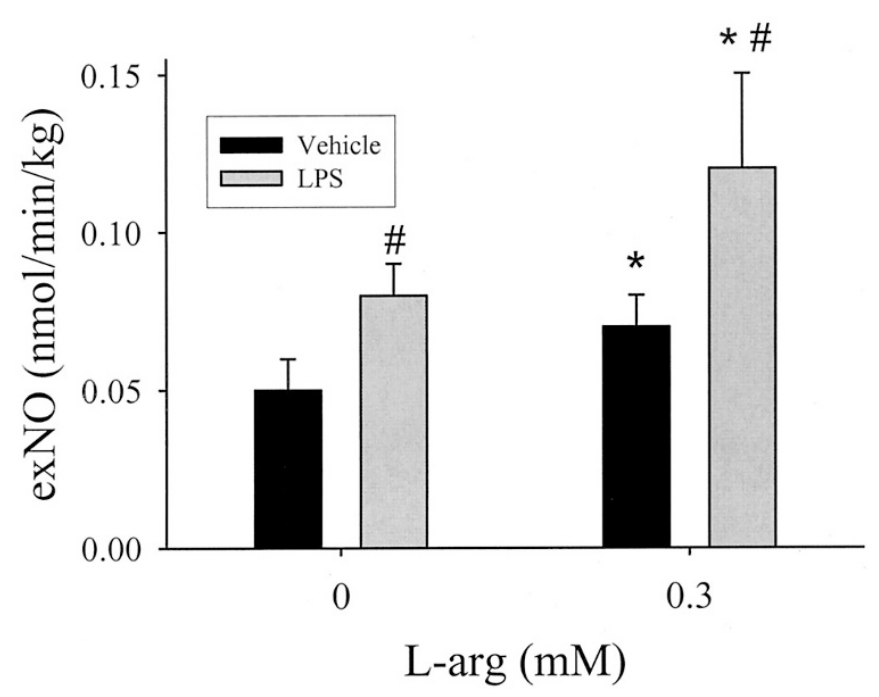

Figure 5. L-Arg increased exNO production in the isolated lung. exNO production before $(0 \mathrm{mM})$ and $20 \mathrm{~min}$ after the addition of $\mathrm{L}$-arg $(0.3 \mathrm{mM}$ final concentration) to the perfusate of lungs isolated from either vehicle-treated ( $\square$ ) or LPS-treated $(\square)$ animals. Values are mean $\pm \operatorname{SE}(n=9$ vehicle and $n=7$ LPS). *0.3 mM L-arg different from $0 \mathrm{mM} \mathrm{L-arg}$ in same group, $p<0.05$; \# LPS-treated different from vehicle-treated at same L-arg concentration, $p<0.05$.

mals, this difference did not reach statistical significance (17.6 $\pm 1.9 \mathrm{~mm} \mathrm{Hg}$ vehicle-treated versus $15.0 \pm 1.6 \mathrm{~mm} \mathrm{Hg}$ LPS-treated). The addition of L-arg to the perfusate had no significant effect on PVR in the vehicle-treated lungs $(0.310 \pm$ $0.039 \mathrm{~mm} \mathrm{Hg} \cdot \mathrm{ml}^{-1} \cdot \mathrm{kg}^{-1} \cdot \min ^{-1} 0 \mathrm{mM}$ L-arg versus 0.301 $\pm 0.050 \mathrm{~mm} \mathrm{Hg} \cdot \mathrm{ml}^{-1} \cdot \mathrm{kg}^{-1} \cdot \min ^{-1} 0.3 \mathrm{mM} \mathrm{L}$-arg). However, the addition of L-arg to the perfusate decreased PVR in all of the lungs studied from LPS-treated animals with a mean decrease of $0.028 \pm 0.008 \mathrm{~mm} \mathrm{Hg} \cdot \mathrm{ml}^{-1} \cdot \mathrm{kg}^{-1} \cdot \mathrm{min}^{-1}$, the mean PVR at $0 \mathrm{mM}$ was $0.261 \pm 0.029 \mathrm{~mm} \mathrm{Hg} \cdot \mathrm{ml}^{-1}$. $\mathrm{kg}^{-1} \cdot \mathrm{min}^{-1}$, and the mean PVR at $0.3 \mathrm{mM}$ was $0.233 \pm$ $0.029 \mathrm{~mm} \mathrm{Hg} \cdot \mathrm{ml}^{-1} \cdot \mathrm{kg}^{-1} \cdot \min ^{-1}(p<0.05)$.

Isolated lungs L-lys and exNO. The exNO production rate with $1 \mathrm{mM}$ L-lys added to the perfusate was significantly greater in the lungs isolated from LPS-treated animals compared with the lungs isolated from vehicle-treated animals (Fig. $6 A$ ). The continued addition of L-lys to the perfusate caused a significant decrease in mean exNO in the lungs isolated from both the LPS- and vehicle-treated animals (Fig. 6A). A concentration of $30 \mathrm{mM} \mathrm{L}$-lys in the perfusate resulted in similar exNO production in LPS- and vehicle-treated lungs (Fig. $6 A$ ). The absolute change in exNO production rate was significantly greater in the lungs from LPS-treated animals compared with lungs from vehicle-treated animals (Fig. 6B).

The addition of L-lys to the perfusate of the lungs isolated from the vehicle-treated animals resulted in no significant change in mean PVR (Fig. 7). However, the addition of L-lys to the perfusate of lungs isolated from LPS-treated animals resulted in a significant increase in mean PVR (Fig. 7A). The mean absolute change in PVR was significant only for the lungs isolated from the LPS-treated animals (Fig. 7B).

To further examine the relationship between the change in exNO to the change in pulmonary vascular tone, we plotted the change in exNO versus the change in Pa (Fig. 8). We used
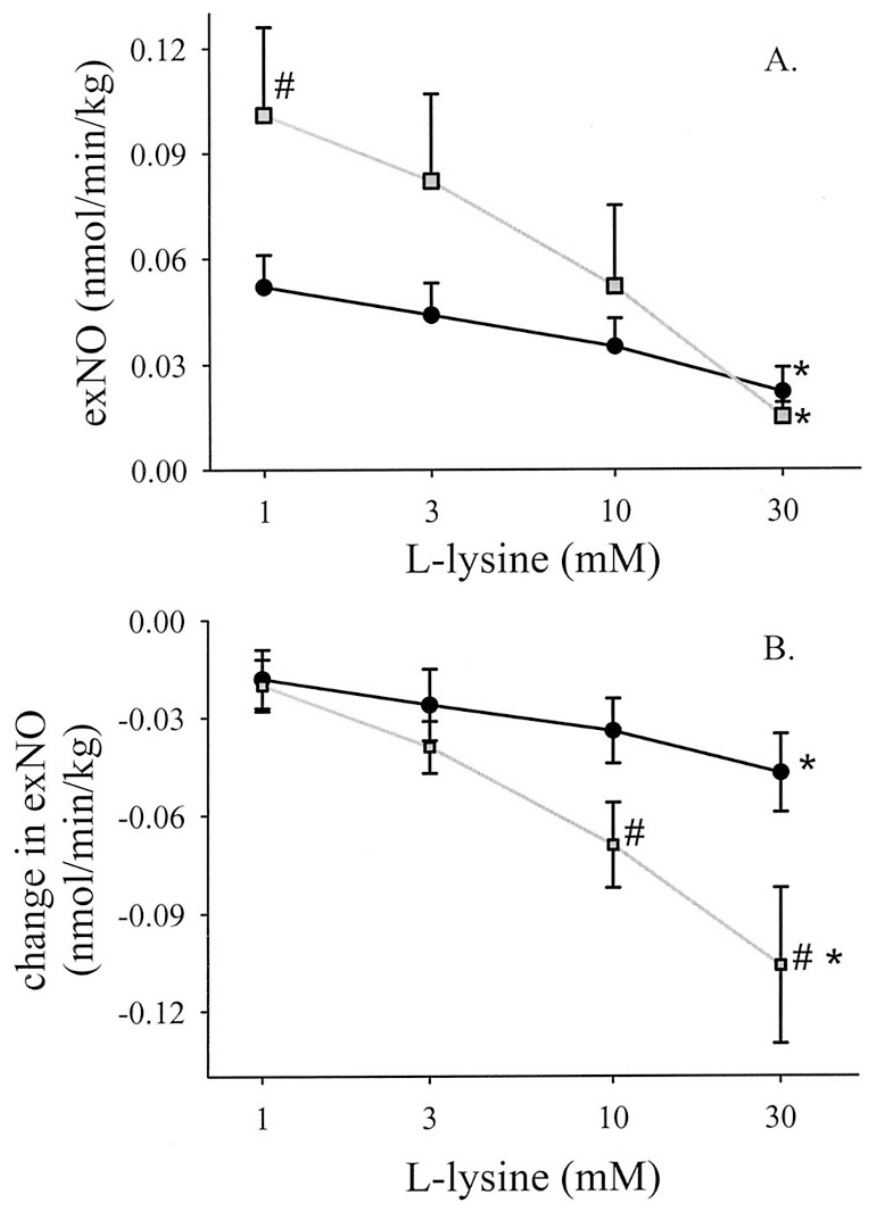

Figure 6. L-Lys decreased exNO production in the isolated lung. $(A)$ The exNO production in the lungs isolated from either vehicle-treated animals (๑) or LPS-treated animals ( $\square$ ) with increasing concentration of L-lys in the perfusate. Values are mean \pm SE $(n=9$ vehicle and $n=7$ LPS). *Different from exNO production at $1 \mathrm{mM}$ L-lys in same group, $p<0.05$; \#LPS-treated different from vehicle-treated at same dose of L-lys, $p<0.05$. $(B)$ The absolute change in exNO production caused by each concentration of L-lys compared with baseline before L-lys addition in the lungs isolated from either vehicle-treated $(\bullet)$ or LPS-treated $(\square)$ animals. Values are mean $\pm \operatorname{SE}(n=9$ vehicle and $n=7$ LPS $)$. *Different from absolute change at $1 \mathrm{mM}$ L-lys in same group, $p<0.05$; \#LPS-treated different from vehicle-treated at same dose, $p<0.05$.

change in Pa because the lungs were perfused at a constant flow rate and a constant pulmonary venous pressure. There was no significant correlation between change in exNO and change in $\mathrm{Pa}$ in the lungs isolated from control animals. However, the change in exNO was negatively correlated $(p<0.01)$ to the change in $\mathrm{Pa}$ in the lungs isolated from pigs treated with LPS, such that the lungs that had the largest decrease in exNO had the greatest increase in Pa (Fig. 8).

Lung CAT-2 mRNA expression. RT-PCR for CAT-2 mRNA demonstrated that LPS treatment resulted in the appearance of a strong CAT-2 mRNA band in all of the isolates tested, whereas all of the isolates from vehicle-treated lungs demonstrated no discernible CAT-2 mRNA band (Fig. 9). The rRNA bands suggest equal RNA concentrations in the starting $\mathrm{RT}$ reactions and demonstrate equal loading in all of the lanes. 

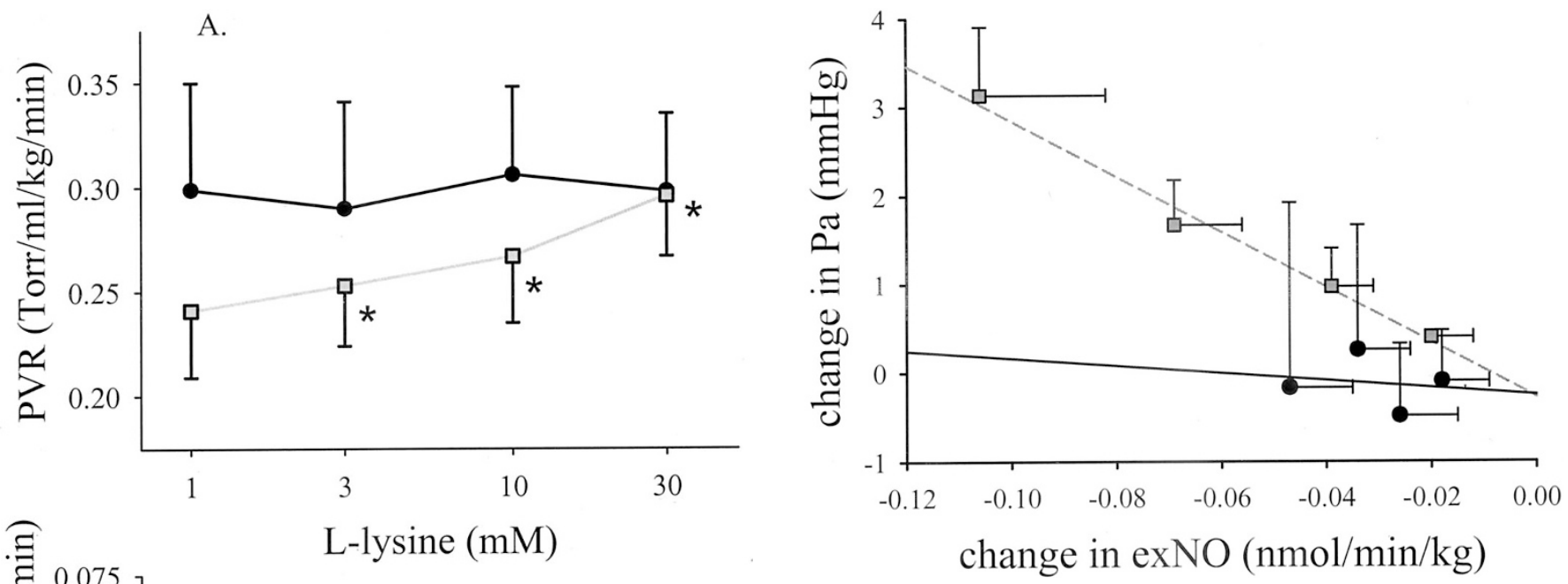

Figure 8. The changes in $\mathrm{Pa}$ and exNO are negatively correlated only in lungs from LPS-treated animals. The mean change in Pa plotted against the mean change in exNO from the isolated lung studies wherein L-lys was added to the perfusate in increasing concentrations. Each point represents the mean results from each of the four L-lys concentrations studied. O, lungs from vehicletreated animals; $\square$, lungs from LPS-treated animals. The solid black line is the regression line for the lungs from vehicle-treated animals, $y=-4.1 x-0.25$, $r=-0.167, p=0.83$. The dashed gray line is the regression line for the lungs from the LPS-treated animals, $y=-31.2 x-0.28, r=-0.993, p<0.01$. In the lungs from the LPS-treated animals, the decreases in exNO are associated with the increases in $\mathrm{Pa}$.

\section{CAT-2 \\ rRNA

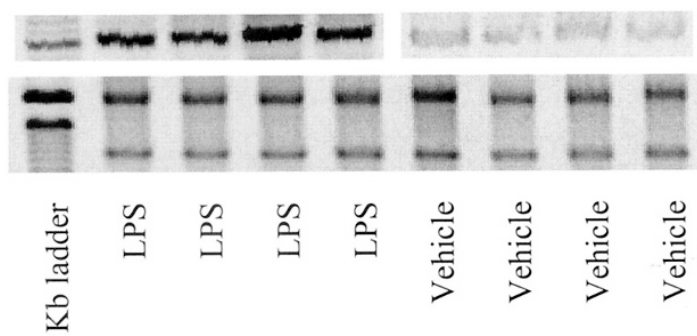

Figure 7. L-Lys increased PVR in lungs isolated from LPS-treated animals. (A) PVR in the lungs isolated from either vehicle-treated (๑) or LPS-treated ( $\square$ ) animals with increasing concentration of L-lys in the perfusate. Values are mean \pm SE ( $n=9$ vehicle and $n=7$ LPS). *Different from PVR at $1 \mathrm{mM}$ L-lys in same group, $p<0.05$. $(B)$ The absolute change in PVR caused by each concentration of L-lys compared with baseline before L-lys addition in the lungs isolated from either vehicle-treated $(\bullet)$ or LPS-treated $(\square)$ animals. Values are mean \pm SE $(n=9$ vehicle and $n=7$ LPS). *Different from absolute change in PVR at $1 \mathrm{mM}$ L-lys in same group, $p<0.05$.

\section{DISCUSSION}

The major findings in this study were that 1 ) LPS treatment increased NO production and reduced MAP in intact neonatal pigs, 2) LPS treatment increased NO production in the isolated lung, 3) adding L-arg to the perfusate of lungs isolated from vehicle- and LPS-treated animals increased NO production, 4) competitive inhibition of $\mathrm{L}$-arg uptake decreased NO production in the lungs isolated from vehicle- and LPS-treated animals, 5) competitive inhibition of L-arg uptake increased PVR only in the lungs isolated from the LPS-treated animals, and 6 ) lung CAT-2 mRNA expression was greater in LPS-treated animals compared with vehicle-treated animals. These results support our hypothesis that the LPS-induced increase in lung NO production rate is dependent on the uptake of extracellular (vascular) L-arg by the CATs. It is interesting that even in the lung from vehicle-treated pig, a portion of lung NO production depends on the uptake of extracellular (vascular) L-arg by the CATs.

In these studies, a relatively large LPS dose $(1 \mathrm{mg} / \mathrm{kg})$ was used. Smaller LPS doses have been reported in many previous experiments in pigs, usually in the range of $1-20 \mu \mathrm{g} / \mathrm{kg}$ (18-20). However, Neumann et al. (21) used a bolus LPS dose of $0.5 \mathrm{mg} / \mathrm{kg}$ i.v. followed by a constant infusion of LPS. Müller et al. (22) reported on the effects of using LPS doses up to $15 \mathrm{mg} / \mathrm{kg}$ i.v. on circulating factors and found that the increase in circulating TNF- $\alpha$ and IL-6 concentrations after LPS were positively correlated with LPS dose at 2 and $4 \mathrm{~h}$ after administration. Because we have previously found that TNF- $\alpha$ is needed for the cytokine-induced increase in L-arg uptake and CAT-2 expression in cultured endothelial cells, we chose a relatively larger dose $(1 \mathrm{mg} / \mathrm{kg})$. Future studies should address the issue of dose effects particularly in terms of increased $\mathrm{NO}$ production and CAT up-regulation.

We found that the exNO concentration was inversely correlated with the MAP and that LPS increased NO production and decreased MAP in the intact pig. Allman et al. (23) found in 
sheep that LPS increased plasma nitrite concentration and decreased systemic vascular resistance and that treatment with a nonspecific NOS inhibitor decreased plasma nitrite concentration and increased systemic vascular resistance. Gundersen et al. (24) found that LPS decreased MAP and that the effect could be inhibited using a selective iNOS inhibitor in intact pigs. Matejovic et al. (18) found that in intact pigs, the infusion of LPS increased expired NO and plasma nitrite levels and decreased MAP and furthermore that the increase in expired NO and plasma nitrite and the decrease in MAP could be prevented using a selective iNOS inhibitor. Taken together, these studies are consistent with the premise that LPS treatment in pigs increased NO production most likely via an increase in iNOS expression and that this increased NO production resulted in a decrease in systemic blood pressure. It is interesting that Fujii et al. (19) found that LPS infusion increased exNO in the pig compared with controls; however, they found that only calcium-dependent NOS activity increased, and furthermore they found no detectable lung iNOS by immunoblotting in either LPS-treated or control animals. Thus, although LPS treatment clearly increased NO production and decreased blood pressure in the intact pig, it remains unclear whether this effect can be attributed exclusively to the induction of iNOS.

Isolated perfused lungs from LPS-treated animals had a greater exNO production rate than did isolated perfused lungs from vehicle-treated animals. This finding is consistent with a recent study by Fischer et al. (25) wherein rats that were given LPS had significantly greater exNO concentrations than rats that were given vehicle. Similarly, Lee et al. (26) found that LPS given to the isolated perfused lung resulted in a dosedependent increase in exNO. Furthermore, our laboratory previously reported that treatment of rats with LPS resulted in the appearance of iNOS mRNA in the lung (27). Similarly, Kaftan et al. (20) found that neonatal pigs that were given LPS had an increase in iNOS protein expression by Western blot analysis. Taken together, these data suggest that LPS treatment resulted in increased NO production by the lung, which was probably due to an increase in iNOS expression in the lung.

We found that in the isolated perfused lung, the addition of L-arg to the perfusate increased NO production. This is consistent with our previous study in cultured bPAEC wherein NO production was increased with increasing media concentration of L-arg (7). Fineman et al. (28) found in isolated perfused lamb lungs preconstricted with the thromboxane mimetic U46619 that the addition of L-arg to the perfusate caused a significant decrease in $\mathrm{Pa}$. In the isolated perfused lungs from neonatal pigs exposed to chronic hypoxia, the addition of L-arg to the perfusate resulted in an increase in NO production and a decrease in PVR (15). The concept that extracellular (vascular) L-arg concentration may affect NO production is also supported by two recent clinical studies. Pearson et al. (29) found that neonatal patients with pulmonary hypertension had lower plasma arginine levels compared with neonatal patients without pulmonary hypertension. McCaffrey et al. (30) found that infusion of a single dose of $\mathrm{L}$-arg increased postductal arterial $\mathrm{PO}_{2}$ in five consecutive neonatal patients with pulmonary hypertension, suggesting that pulmonary blood flow increased with L-arg infusion. Taken together, these studies suggest that, at least under certain conditions, the bioavailability of vascular L-arg as a substrate for NOS may be rate limiting for NO production.

Inhibition of L-arg uptake resulted in a decrease in exNO production in the isolated perfused lungs. L-Lys decreased exNO in lungs isolated from LPS-treated pigs to a greater extent than in lungs isolated from vehicle-treated pigs. This could be consistent with simply starting at a greater exNO production rate in the LPS-treated lungs, or it may be that in a condition of increased NO production that NOS activity becomes more dependent on extracellular L-arg as a source of substrate. This interpretation is consistent with a study by Simmons et al. (9) in cultured myocytes, wherein L-lys decreased NO production only in cells that were stimulated by IL- 1 and interferon- $\gamma$. However, L-lys also decreased exNO production in the lungs from vehicle-treated animals, suggesting that extracellular L-arg is involved even in basal NO production in the pig lung. This concept is consistent with previous studies in cultured pulmonary arterial endothelial cells wherein increasing the extracellular L-arg concentration increased NO production even in untreated cells (7). Taken together, these studies indicate that inhibition of cationic amino acid transport limits substrate availability to NOS, resulting in decreased NO production.

In the isolated perfused lungs from LPS-treated animals, there was a significant increase in PVR with the addition of L-lys to the perfusate. To the best of our knowledge, no previous studies have examined the effect of L-lys in isolated perfused lungs. In intact sheep, Allman et al. (31) found that $500 \mathrm{mg} / \mathrm{kg}$ L-lys given i.v. over $1 \mathrm{~h}$ and followed by an additional $500 \mathrm{mg} / \mathrm{kg}$ infused over $8 \mathrm{~h}$ had no effect on MAP or plasma nitrite concentration, whereas in intact rats, Liaudet et al. (32) found that $500 \mu \mathrm{mol} \cdot \mathrm{kg}^{-1} \cdot \mathrm{h}^{-1} \mathrm{~L}$-lys infused for $5 \mathrm{~h}$ resulted in an increase in MAP and a decrease in plasma nitrate and L-citrulline concentrations. These different results may reflect species differences or L-lys concentration differences. In our preparation, the L-arg concentration in the perfusate was $\sim 300 \mu \mathrm{M}$, whereas the concentration of L-lys used was up to $30 \mathrm{mM}$; thus, L-lys was in excess in our preparation, and we found a decrease in NO production. It seems that, at least in some models of LPS-induced NO production, inhibiting L-arg uptake will decrease NO production and increase PVR.

The change in PVR was inversely correlated with the change in exNO production only in the lungs from LPS-treated animals; that is, the lungs with the greatest decrease in exNO as a result of L-lys had the greatest increase in $\mathrm{Pa}$. We chose to measure exNO production as a measure of lung NO production on the basis of our previous results in 2-wk-old neonatal pigs demonstrating that measurement of exNO production is a sensitive, rapidly responding measure of physiologically relevant lung NO production $(16,33,34)$. This finding is consistent with studies from other laboratories $(19,26,35-37)$. Conversely, we recently found that in younger pigs (age 3-4 d), exNO production was decreased by chronic hypoxia but perfusate NOx (nitrites/nitrates) production was unaffected, and chronic hypoxia decreased only eNOS and nNOS protein levels in the airways (34). This finding suggests that there may 
be conditions wherein the exNO production is not a reflection of vascular NO production. However, the point to measuring exNO was to determine physiologically relevant lung NO production. Although it would be of interest to determine the exact location of the LPS-induced increase in exNO production, these studies are beyond the scope of this article. Our finding of an inverse correlation of exNO and $\mathrm{Pa}$ are consistent with the interpretation that in a condition of increased $\mathrm{NO}$ production, NOS activity becomes more dependent on extracellular L-arg as a source of substrate.

Further evidence that L-arg uptake is important in the LPSinduced increase in NO production comes from our RT-PCR data, wherein we found that LPS caused an increase in CAT-2 mRNA expression compared with controls. This finding is consistent with studies in cultured vascular smooth muscle cells and cardiac myocytes wherein CAT-2 mRNA expression was up-regulated after cytokine stimulation $(6,9)$. We previously demonstrated that treatment of bPAEC with LPS and TNF- $\alpha$ significantly increased CAT- 2 mRNA expression and that the increased expression of CAT-2 in bPAEC was associated with an increase in L-arg uptake from the medium (7). Furthermore, peritoneal macrophages isolated from CAT-2 knockout mice $\left(\mathrm{CAT}-2^{-/-}\right.$) activated by cytokines demonstrated only $5 \%$ of the L-arg uptake and only $8 \%$ of the NO production observed in similarly activated peritoneal macrophages from wild-type mice, despite equal amounts of iNOS protein and activity in the peritoneal macrophages from CAT $-2^{-1-}$ and wild-type mice (38). Taken together, these results suggest that increased CAT-2 transporter expression is involved in the LPS-induced increase in NO production. Further characterization of the signal transduction pathways responsible for the regulation of CAT-2 expression may provide insight into the mechanisms involved in cytokineinduced, L-arg transport-dependent increased NO production seen in these lungs.

\section{CONCLUSION}

In conclusion, the current study demonstrates the utility of LPS treatment in neonatal pigs as a model for increased pulmonary NO production. We found that increasing the vascular L-arg concentration increased lung NO production in both control and LPStreated lungs. Furthermore, these experiments provided evidence for the first time that inhibiting L-arg uptake using L-lys decreased NO production in the neonatal pig lung. In the LPS-treated lungs, the decrease in NO production rate caused by L-lys was associated with an increase in PVR. Moreover, LPS treatment of neonatal pigs increased CAT-2 mRNA expression in the lung. Thus, NO production in these animals depends on extracellular L-arg, because increasing the vascular $\mathrm{L}$-arg concentration increased $\mathrm{NO}$ production and inhibiting the uptake of vascular L-arg decreased NO production. Furthermore, the up-regulation of CAT- 2 mRNA may represent a mechanism to maintain L-arg availability to NOS in this model of LPS-induced increased NO production. We speculate that interruption of L-arg uptake or expression of L-arg transporters may represent future therapeutic targets in diseases characterized by NO overproduction such as septic shock and acute respiratory distress syndrome.
Acknowledgments We thank Kelly Billings for excellent technical assistance and Prof. Benjimen R. Walker for assistance with study design.

\section{REFERENCES}

1. Aaron SD, Valenza F, Volgyesi G, Mullen JB, Slutsky AS, Stewart TE 1998 Inhibition of exhaled nitric oxide production during sepsis does not prevent lung inflammation. Crit Care Med 26:309-314

2. Kirkeboen KA, Strand OA 1999 The role of nitric oxide in sepsis. Acta Anesthesiol Scand 43:275-288

3. Stoclet JC, Martinez MC, Ohlmann P, Chasserot S, Schott C, Kleschyov AL, Schneider F, Andriantsitohaina R 1999 Induction of nitric oxide synthase and dual effects of nitric oxide and cyclooxygenase products in regulation of arterial contraction in human septic shock. Circulation 100:107-112

4. Vincent JL, Zhang H, Szabo C, Preiser JC 2000 Effects of nitric oxide in septic shock. Am J Respir Crit Care Med 161:1781-1785

5. Bogle RG, Baydoun AR, Pearson JD, Moncada S, Mann GE 1992 L-arginine transport is increased in macrophages generating nitric oxide. Biochem $\mathrm{J} 284: 15-18$

6. Gill DJ, Low BC, Grigor MR 1996 Interleukin-1 and tumor necrosis factor stimulate the CAT-2 gene of the L-arginine transporter in cultured vascular smooth muscle cells. J Biol Chem 271:11280-11283

7. Nelin LD, Nash HE, Chicoine LG 2001 Cytokine treatment increases arginine metabolism and uptake in bovine pulmonary arterial endothelial cells. Am J Physiol Lung Cell Mol Physiol 281:L1232-L1239

8. Nelin LD, Krenz GS, Chicoine LG, Dawson CA, Schapira RM 2002 L-arginine uptake and metabolism following in vivo silica exposure in rat lungs. Am J Respir Cell Mol Biol 26:348-355

9. Simmons WW, Closs EI, Cunningham JM, Smith TW, Kelly RA 1996 Cytokines and insulin induce cationic amino acid transporter CAT expression in cardiac myocytes. J Biol Chem 271:11694-11702

10. Stathopulos PB, Lu X, Shen J, Scott JA, Hammond JR, McCormack DG, Arnold JM, Feng Q 2001 Increased L-arginine uptake and inducible nitric oxide synthase activity in aortas of rats with heart failure. Am J Physiol Heart Circ Physiol 280:H895-H867

11. Wang H, Kavanaugh MP, North RA, Kavat D 1991 Cell surface receptor for ecotropic murine retroviruses is a basic amino acid transporter. Nature 352:729-731

12. Devés R, Boyd CAR 1998 Transporters of cationic amino acids in animal cells: discovery, structure and function. Physiol Rev 78:487-545

13. Block ER, Herrera H, Couch M 1995 Hypoxia inhibits L-arginine uptake by pulmonary artery endothelial cells. Am J Physiol 269:L574-L580

14. Hattori Y, Kasai K, Gross SS 1999 Cationic amino acid transporter gene expression in cultured vascular smooth muscle cells and in rats. Am J Physiol 276:H2020-H2028

15. Fike CD, Kaplowitz MR, Rehorst-Paea LA, Nelin LD 2000 L-arginine increases nitric oxide production in isolated lungs of chronically hypoxic newborn pigs. J Appl Physiol 88:1797-1803

16. Nelin LD, Thomas CJ, Dawson CA 1996 The effect of hypoxia on nitric oxide production in the neonatal pig lung. Am J Physiol 271:H8-H14

17. Nelin LD, Dawson CA 1993 The effect of N $\omega^{-}$nitro-L-arginine methylester on hypoxic vasoconstriction in the neonatal pig lung. Pediatr Res 34:349-353

18. Matejovic M, Radermacher P, Tugtekin I, Stehr A, Theisen M, Vogt J, Wachter U, Ploner F, Georgieff M, Trager K 2001 Effects of selective iNOS inhibition on gut and liver $\mathrm{O}_{2}$-exchange and energy metabolism during hyperdynamic porcine endotoxemia. Shock 16:203-210

19. Fujii Y, Goldberg P, Hussain SN 1998 Intrathoracic and extrathoracic sources of exhaled nitric oxide in porcine endotoxemic shock. Chest 114:569-576

20. Kaftan HA, Clark PL, Norberg M, Garg U, Thibeault DW, Truog WE 2003 Endogenous production of nitric oxide in endotoxemic piglets. Biol Neonate 83:42-48

21. Neumann P, Berglung JE, Mondéjar EF, Magnusson A, Hedenstierna G 1998 Dynamics of lung collapse and recruitment during prolonged breathing in porcine lung injury. J Appl Physiol 85:1533-1543

22. Müller G, Steinbach G, Berndt A, Köhler 2002 Effects of various applications of lipopolysaccharides on blood parameters of pigs. J Vet Med B Infect Dis Vet Public Health 49:429-437

23. Allman KG, Stoddart AP, Kennedy MM, Young JD 1996 L-arginine augments nitric oxide production and mesenteric blood flow in ovine endotoxemia. Am J Physiol 271:H1296-H1301

24. Gundersen Y, Saetre T, Scholz T, Hovig T, Lilleaasen P, Aasen AO 1999 Selective inhibition of inducible nitric oxide synthase maintains haemodynamic stability without untoward consequences for hepatic function or morphology. Eur J Surg 165:1167-1174

25. Fischer LG, Horstman DJ, Hahnenkamp K, Kechner NE, Rich GF 1999 Selective iNOS inhibition attenuates acetylcholine- and bradykinin-induced vasoconstriction in lipopolysaccharide-exposed rat lungs. Anesthesiology 91:1724-1732

26. Lee RP, Wang D, Kao SJ, Chen HI 2001 The lung is the major site that produces nitric oxide to induce pulmonary oedema in endotoxin shock. Clin Exp Pharmacol Physiol 28:315-320

27. Resta TC, O’Donaughy TL, Earley S, Chicoine LG, Walker BR 1999 Unaltered vasoconstrictor responsiveness after iNOS inhibition in lungs from chronically hypoxic rats. Am J Physiol Lung Cell Mol Physiol 276:L122-L130

28. Fineman JR, Chang R, Soifer SJ 1991 L-arginine, a precursor of EDRF in vitro, produces pulmonary vasodilation in lambs. Am J Physiol 261:H1563-H1569

29. Pearson DL, Dawling S, Walsh WF, Haines JL, Christman BW, Bazyk A, Scott N, Summar ML 2001 Neonatal pulmonary hypertension-urea cycle intermediates, nitric oxide production, and carbamoyl-phosphate synthetase function. N Engl J Med $344: 1832-1838$ 
30. McCaffrey MJ, Bose CL, Reiter PD, Stiles AD 1995 Effect of L-arginine infusion on infants with persistent pulmonary hypertension of the newborn. Biol Neonate 67:240-243

31. Allman KG, Stoddart AP, Young JD 1998 Effect of L-lysine on nitric oxide production in ovine endotoxaemia. Br J Anaesth 81:188-192

32. Liaudet L, Gnaegi A, Rosselet A, Mankert M, Boulat O, Perret C, Feihl F 1997 Effect of L-lysine on nitric oxide overproduction in endotoxic shock. Br J Pharmacol 122:742-748

33. Fike CD, Kaplowitz MR, Thomas CJ, Nelin LD 1998 Chronic hypoxia decrease nitric oxide production and endothelial nitric oxide synthase in newborn pig lungs. Am J Physiol 274:L517-L526

34. Turley JE, Nelin LD, Kaplowitz MR, Zhang Y, Fike CD 2003 Exhaled NO is reduced at an early stage of hypoxia-induced pulmonary hypertension in newborn piglets. Am J Physiol Lung Cell Mol Physiol 284:L489-L500
35. Carlin RE, Ferrario L, Boyd JT, Camporesi EM, McGraw DJ, Hakim TS 1997 Determinants of nitric oxide in exhaled gas in the isolated rabbit lung. Am J Respir Crit Care Med 155:922-927

36. Ogasa T, Nakano H, Ide H, Yamamato Y, Sasaki N, Osanai S, Akiba Y, Kikuchi K, Iwamoto J 2001 Flow-mediated release of nitric oxide in isolated, perfused rabbit lungs. J Appl Physiol 91:363-370

37. Vaughn DJ, Brogan TV, Kerr ME, Deem S, Luchtel DL, Swenson ER 2003 Contributions of nitric oxide synthase isozymes to exhaled nitric oxide and hypoxic pulmonary vasoconstriction in rabbit lungs. Am J Physiol Lung Cell Mol Physio 284:L834-L843

38. Nicholson B, Manner CK, Kleeman J, MacLeod CL 2001 Sustained nitric oxide production in macrophages requires the arginine transporter CAT2. J Biol Chem 276:15881-15885 